\title{
Avaliacão da implantação do programa de desenvolvimento integrado em Manguinhos: impasses na formulação de uma agenda local
}

\author{
Evaluation of the implementation of the integrated \\ development program in Manguinhos: impasses \\ in the formulation of a local agenda
}

\author{
Regina Bodstein 1 \\ Lenira Zancan 1 \\ Célia Leitão Ramos 1 \\ Willer Baumgarten Marcondes 2
}

\footnotetext{
1 Departamento

de Ciências Sociais. Escola Nacional de Saúde Pública Rua Leopoldo Bulhões 1.480, sala 915, Manguinhos, 21041-210,Rio de Janeiro RJ. Bodstein@ensp.fiocruz.br

2 Doutorando em Saúde Pública, bolsista CNPq, Escola Nacional de Saúde Pública, Fiocruz.
}

Abstract This paper deals with the implantation of the Integrated and Sustainable Development Program in Manguinhos, a low-income, densely populated urban area, through the combined action of partners from different public sectors, private activities and civil society. The program was intended to give support to intersectorial projects and actions of health promotion focused on the local population. The evaluation took as main references the implantation of programs at community level, where was pointed out the significant role played by mobilization, constitution of a new setting of interaction and collective action, involving local leaderships, in establishing a common agenda. On this basis, the authors discuss the evidences found related to associative life and the dynamics involved in setting up a Regional Forum. The analysis revealed the impasses in the local policy process affecting the relationships and the collective actions vis-à-vis a situation in which there is a lacking of intersectorial initiatives and action. Both the mobilization and the organization of the population - together with overcome a state of high-level violence and the current pattern of sociability, unclenching a process where more effective measures in health promotion can be found in Manguinhos.

Key words Evaluation, Health promotion programs, Community initiatives on health promotion
Resumo O artigo discute a implantação do programa de Desenvolvimento Integrado e Sustentável em Manguinhos, iniciado através da constituição de parcerias entre poder público, iniciativa privada e organizações sociais, visando às politicas e ações intersetoriais de promoção da saúde nas comunidades da região. A avaliação tomou como referência a discussão sobre a implantação do programa e a importância do contexto, considerando as dimensões da mobilização dos atores, da constituição de um espaço de interlocução e de ação coletiva entre as lideranças locais, objetivando uma agenda comum. Foi feita uma análise da vida associativa e da dinâmica de constituição do chamado Fórum Regional, que representou um esforço de agregação destes atores e lideranças da região. A análise revelou uma fragilidade nas relações e ações coletivas vis-à-vis a ausência da implementação de ações públicas intersetoriais. Mobilização, organização social e mudanças institucionais foram vistos como fatores cruciais para equacionar o problema da violência e do padrão alterado de sociabilidade local, desencadeando medidas mais efetivas de promoção da saúde e de melhoria na qualidade de vida em Manguinhos.

Palavras-clave Avaliação de programas sociais, Programas de promoção da saúde, Desenvolvimento comunitário, Participação comunitária em programas sociais 


\section{Introdução}

Experiências de desenvolvimento local (DLIS) vêm ocorrendo no Brasil na última década (Krutman, 2004) em um contexto de fortalecimento das organizações da sociedade civil e de controle social, nas quais se observa uma maior preocupação com a efetividade e eficiência das ações sociais no País. A preocupação com a racionalidade do gasto, através de ações que assegurem impacto externo, e a eficiência interna das iniciativas sociais envolvem o monitoramento e a avaliação, instigando o debate e a discussão sobre os princípios que orientam as propostas e os resultados e efeitos alcançados.

Programas de DLIS e de promoção da saúde surgem, nesse contexto, a partir de propostas interdisciplinares e objetivos multifocais, com ênfase na intersetorialidade e na participação, em que componentes de geração de renda, segurança pública, demandas socioculturais, ambientais e de redução da desigualdade ganham destaque (Buss \& Ramos, 2000; Buss, 1999; Potvin \& Richard, 2001). Têm como fundamento um conjunto de valores e princípios como a eqüidade e o empowerment, implicando o desenho de programas voltados para mudanças sociais abrangentes (Rootman et al., 2001). Estratégias de mobilização e de envolvimento das comunidades no processo de mudança são centrais, pressupondo ampla participação social desde a elaboração de um diagnóstico local até a formulação, implementação e monitoramento das ações. Propondo gestão integrada nos diversos níveis da administração pública (federal, estadual e municipal), formação de parcerias e participação comunitária, esses programas são particularmente complexos não só pela multiplicidade de iniciativas, propostas e atores, mas sobretudo porque explicitam um compromisso com a sustentabilidade das ações no médio e longo prazo (Potvin \& Richard, 2001; Sullivan et al., 2002). Como veremos no caso de Manguinhos, têm como efeito indireto a superação de propostas meramente assistencialistas e práticas políticas tradicionais que tendem a aprofundar relações de dependência e de subordinação da população beneficiada. Enfim, trazem como valores a ampliação do espaço decisório e dos direitos da cidadania a partir de uma nova dinâmica capaz de envolver o conjunto das organizações sociais presentes e atuantes no local (Barnes et al., 2003).
Diante de suas múltiplas dimensões constituem um permanente desafio aos enfoques avaliativos tradicionais que têm como característica identificar e medir resultados e efeitos. Implicam a necessidade de revisão e de ampliação dos esquemas e conceitos consagrados no campo da avaliação e de busca de novas abordagens (Pawson, 2003; Rootman et al., 2001; Potvin et al., 2001; Barnes et al., 2003).

A literatura recente sobre avaliação de políticas sociais e de programas de promoção da saúde e de desenvolvimento comunitário chama a atenção para a dinâmica altamente complexa desses programas, colocando os inúmeros desafios metodológicos em jogo (Barnes et al., 2003; Potvin et al., 2001). O caráter abrangente, mutante e reflexivo, envolvendo inúmeros atores, interesses e conflitos, tem sido destacado onde mudanças na agenda e nos rumos do programa são constantes. Ações intersetoriais, objetivos multiestratégicos, mudanças sociais abrangentes, objetivos que se desdobram constantemente, mobilização e organização comunitária, são aspectos freqüentemente levantados. Questões em torno da sustentabilidade política dos programas também têm adquirido relevância nas análises recentes (Pluye et al., 2004).

A perspectiva de avaliar ou de descrever a dinâmica da implantação de programas complexos traz uma enorme contribuição na medida em que enfatiza a importância do contexto e, portanto, dos fatores sociais e dos interesses políticos em jogo. Apresenta como questão central a compreensão de como os programas foram desenhados, suas dimensões ou componentes de fato implementados e modificados (Hartz, 1999; Denis \& Champagne, 1997; Rootman et al., 2001). Tem o mérito de mostrar que o contexto em que o programa está inserido tem profundas implicações não só nas condições de sua implantação, mas, fundamentalmente, nas mudanças produzidas, ressaltando os limites analíticos de uma avaliação baseada unicamente nos efeitos e nos impactos observáveis da intervenção (Denis \& Champagne, 1997; Pawson \& Tilley, 1997). Há o claro reconhecimento de que efeitos e impactos dos programas são freqüentemente indiretos, e que o fundamental, principalmente em programas complexos, é a análise dos fatores que influenciam os resultados obtidos (Denis \& Champagne, 1997). McKinlay (1996), discutindo métodos de avaliação mais apropriados para iniciativas de desenvolvimento comunitário, lembra que não só processos determinam resultados, 
mas que o importante é perceber em que medida o programa foi adequadamente implementado nas dimensões propostas.

O foco na implantação de programas está, em certa medida, compreendido naquilo que a literatura tradicionalmente define como "avaliação de processo", sendo central também para a metodologia de análise de políticas (Majchrzak, 1984). Especialmente nos casos de programas comunitários multiestratégicos, a avaliação de processo tem o potencial de explicar e trazer evidências sobre os impasses e os rumos que as intervenções adquirem em contextos específicos. Os estudos de caso são particularmente adequados na perspectiva de avaliar a implementação de políticas (Hakin, 1999). Na perspectiva de Denis \& Champagne (1997), a análise de implantação é tratada em seu aspecto relacional com o contexto sócio-organizacional e os efeitos observados.

Questão central em torno da complexidade do contexto diz respeito às carências sociais básicas e os níveis crescentes de violência que vêm desafiando as diversas administrações públicas, gerando um círculo vicioso e persistente de exclusão social. Trata-se de questões que exigem de fato novos investimentos públicos em serviços sociais e infra-estrutura urbana de difícil solução a curto prazo. Tal é o caso de Manguinhos - e da maioria das comunidades situadas na região metropolitana do Rio de Janeiro -, que concentra um contingente considerável de população de baixa renda, em um contexto social extremamente desafiador, já que, como nos revela Zaluar em sua discussão sobre exclusão e políticas públicas em áreas faveladas do Rio de Janeiro,

[...] é preciso sobretudo restaurar as redes locais de reciprocidade positiva, reforçar as solidariedades enfraquecidas entre as gerações, intra e extra-classe, assim como, nas políticas públicas, abrir espaço político para reconhecer e estabelecer parcerias com todas as formas de associações que promovem aquelas reciprocidades e solidariedades (Zaluar, 1997).

Dessa forma, um dos objetivo deste artigo é chamar a atenção para a complexidade dos programas de promoção da saúde e das abordagens avaliativas diante desse contexto. Além disso, trata de apresentar e discutir a metodologia de avaliação do DLIS -Manguinhos a partir da análise das principais estratégias de implantação do Programa:

- implementação das parcerias e ações intersetoriais;
- mobilização das lideranças locais, através do Diagnóstico Rápido Participativo (DRP) e elaboração do Guia de Equipamentos e Iniciativas Sociais, visando à identificação e à discussão dos projetos e propostas em curso na área e, finalmente;

- constituição do Fórum Regional e elaboração de uma agenda integrada.

A avaliação consistiu, em termos gerais, na compreensão dos padrões de intermediação de interesses e relações de confiança (ou desconfiança) que perpassam a vida associativa e as práticas políticas em Manguinhos, fundamentais para a formulação de uma agenda integrada. Essas características, como veremos, definem o sentido que o programa adquire no local e os impasses e limites no processo de mudança. Em termos metodológicos, a avaliação esteve voltada, portanto, para a análise de possíveis mudanças no sentido da ampliação da ação coletiva e do espaço público local (Putnam, 1996).

A experiência de Manguinhos mostrou que sem um processo de discussão e mobilização das lideranças comunitárias é impossível levar a efeito iniciativas de caráter abrangente e com inúmeros atores e parceiros para uma região marcada pela exclusão dos direitos básicos de cidadania, num ambiente de extrema violência. Evidenciou, assim, a importância de tomar como ponto de partida um diagnóstico participativo, isto é, um mapeamento das principais formas de organização coletivas e de solidariedade, seus principais atores e lideranças, interesses convergentes, bem como relações de conflito já estabelecidas.

A análise da implantação do DLIS em Manguinhos mostrou que se em um primeiro momento, mobilização, discussão e adesão à proposta pelas lideranças locais foi um processo relativamente simples e imediato, posteriormente, a cooperação necessária para a negociação de uma agenda comum junto com os demais parceiros do programa enfrentou inúmeros impasses e desafios, como discutiremos à frente.

\section{Contexto do programa}

Abrigando uma população em torno de 35 mil habitantes concentrada em mais de onze comunidades, algumas em condições de extrema precariedade, miséria e exclusão social, Manguinhos, como as demais áreas de população 
favelada da cidade do Rio de Janeiro, concentra os principais problemas relacionados à insuficiência de renda e péssima qualidade de serviços públicos em setores tais como, educação, saúde, infra-estrutura urbana, cultura, lazer e segurança pública. Com graves problemas habitacionais e ambientais, sem falar no desemprego e na violência, esses locais constituem um desafio crescente à administração e a segurança pública da cidade.

Nesse contexto, o DLIS - Manguinhos teve como referência e inspiração o fato de que para promover saúde (...) é absolutamente necessário se conhecer e agir sobre seus principais determinantes (...) os determinantes da saúde estão visceralmente ligados às condições concretas de vida, e adquirem extrema materialidade no nivel local [...] De outro lado, explorando o que se conhece sobre os determinantes da saúde verificase que inúmeros fatores transcendem a esfera pessoal/individual para alcançar o social/coletivo $e$, portanto, a esfera do Estado e da organização da sociedade (Ferreira \& Buss, 2002).

O Programa, portanto, levou em consideração a multiplicidade de fatores determinantes da saúde e da qualidade de vida e a possibilidade de se implementar ações multissetoriais efetivas na região, reforçando a cidadania e a vida associativa. De fato, o pressuposto é de que desenvolvimento local e promoção da saúde caminham juntos e ganham concretude através da concentração de iniciativas e benefícios em uma mesma região.

Experiências e metodologias de avaliação de programas com esse perfil vêm sendo bastante discutidas como é o caso das Health Action Zones (HAZs) (Barnes et al., 2003; Pawson, 2002; Sullivan et al., 2002). As HAZs implantadas desde 1997 pelo governo trabalhista em vários regiões da Grã-Bretanha, apresentam objetivos convergentes com o DLIS, a saber: bring together all those contributing to the health of the local population to develop and implement a locally agreed strategy for improving the health of local people (Department of Health, 1997:1 apud Sullivan et al. 2002).

No caso de Manguinhos, especial ênfase foi dada às áreas em condições ambientais e habitacionais altamente degradadas, de risco à saúde e de grande vulnerabilidade social através de projetos de urbanização vis-à-vis a introdução de práticas inovadoras de saúde, com a implantação do Programa Saúde da Família (PSF) e gradual reorientação do Centro de Saúde da ENSP/Fiocruz (Reis et al., 2002). Por outro la- do, a ampliação e melhoria do acesso aos serviços básicos de educação, saúde, saneamento e segurança pública, indicadores de êxito de qualquer proposta de desenvolvimento social, dependendo de novos investimentos também estavam previstas (Bodstein \& Zancan, 2003). Assim, acesso à creche, melhoria no saneamento, ociosidade dos jovens, prevenção de gravidez na adolescência e geração de trabalho e renda são questões centrais. Um dado relevante no contexto de Manguinhos é, sem dúvida, a situação de falência dos diversos níveis da administração pública em suprir as comunidades (e de resto as demais favelas da cidade do Rio de Janeiro) com uma infra-estrutura de serviços sociais de qualidade, recuperando os déficits já existentes, planejando a expansão das necessidades, enfim, integrando estas comunidades aos bairros da cidade. A complexidade da questão social em Manguinhos foi tratada como uma característica central do programa e da proposta avaliativa, já que a exclusão social e a violência alteram os padrões de sociabilidade e de negociação de conflitos (Zaluar, 1997). Promover a interlocução das lideranças comunitárias com os demais parceiros do programa, assim como uma participação mais democrática e efetiva do poder público foi um dos principais desafios da proposta DLIS-Manguinhos, dado o alto grau de violência presente no local. Considerando que a complexidade do contexto pode ser interpretado a partir de diferentes perspectivas, a identificação dos principais atores, conflitos e interesses presentes no local constitui-se em uma etapa prévia necessária.

Assim, o que importa destacar, no nosso caso, mais do que resultados, foram as dificuldades e obstáculos na consolidação de um espaço de interlocução e negociação de uma agenda de desenvolvimento local. Nessa perspectiva, foram destacadas algumas dimensões e etapas que nos pareceram centrais para o rumo do programa e, portanto, relevantes para a pesquisa avaliativa, pois revelam, de forma indutiva, potenciais problemas e fatores facilitadores a serem considerados pelo avaliador no modelo teórico das intervenções.

Em resumo, o processo de implantação do programa em Manguinhos caracterizou-se por dois momentos distintos mas interdependentes: - Mobilização de entidades públicas e privadas com o compromisso de definir e integrar ações em benefício do desenvolvimento local;

- Mobilização das lideranças comunitárias através da criação do Fórum Regional para a 
negociação de uma agenda comum, visando garantir uma maior adequação das propostas às demandas e a situação social da área.

\section{Mobilização de entidades}

A constituição de um processo de interlocução entre iniciativas públicas e privadas e organizações sociais locais marcou desde o início a proposta de DLIS-Manguinhos, no final de 1999, enfatizando o caráter inovador da experiência de promoção da saúde e de desenvolvimento no local. O programa, procurando ampliar as parcerias, define, já nessa época, objetivos abrangentes, integrando perspectivas, estratégias e demandas dos diversos parceiros. Assim, cabe mencionar os objetivos definidos ainda em 1999:

- Identificar, articular e integrar as diversas iniciativas de desenvolvimento econômico e social presentes no conjunto das comunidades;

- Promover o processo de interlocução e coresponsabilização entre o poder público, as entidades privadas e a população organizada, através da constituição de instâncias de gestão das políticas de desenvolvimento local;

- Gerar e disponibilizar informações, metodologias e tecnologias em DLIS, a partir da experiência de Manguinhos (Bodstein \& Zancan, 2003).

Após estratégia inicial de mobilização e sensibilização das entidades envolvidas, definiu-se como primeiro passo o mapeamento das ações de cada entidade parceira com o objetivo de promover o diálogo e otimizar os recursos disponíveis e buscar novas parcerias em função das necessidades e prioridades locais. O movimento de articulação, resultou em um elenco de ações e propostas a partir do qual foi realizada uma consulta às lideranças locais, através de ampla reunião convocada pela subprefeitura da região.

A agenda constituiu-se em uma primeira sistematização das diversas ações já em desenvolvimento, propostas pelas instituições públicas e empresas locais, possibilitando identificar a convergência de ações, com foco na criança e no adolescente. Cabe destacar a forte presença de iniciativas de ampliação da escolaridade, capacitação profissional e dinamização de atividades de arte, esporte e lazer entre as propostas que deveriam ser implementadas no âmbito do DLIS/Manguinhos.

Em decorrência desta lógica intersetorial e participativa, buscou-se definir estratégias para o conjunto do Programa, além do esforço de garantir recursos para implementar e/ou ampliar os projetos já definidos no âmbito de cada secretaria municipal e dos demais parceiros envolvidos. Esta perspectiva de intervenção exigia a criação de mecanismos de articulação mais dinâmicos no interior do DLIS-Manguinhos, reforçando a idéia de constituição de diversos fóruns de desenvolvimento que cumprissem a função de aglutinar tanto os parceiros, como a população organizada em torno da redefinição da agenda local. Nesse processo, foi delineada a seguinte estratégia de gestão do programa:

- Fórum Comunitário Local: fórum de cada comunidade do Complexo visando à discussão de seus problemas e à mobilização para constituição do Fórum Regional de Manguinhos;

- Fórum Regional de Manguinhos: composto por quatro representantes de cada comunidade, eleitos nos Fóruns Comunitários Locais;

- Conselho de Desenvolvimento: instância de encontro de representantes do Fórum Regional e instituições parceiras do DLIS-Manguinhos para a deliberação de propostas e meios de execução;

- Secretaria Executiva: responsável pela logística necessária à organização e circulação de informações relevantes acerca das deliberações do Conselho de Desenvolvimento.

Importa destacar que na discussão e mobilização inicial em torno da implantação do DLIS, ou seja, no decorrer dos anos de 2000 e 2001, um número de parceiros significativamente grande e altamente diversificado foi envolvido, a saber: representantes das três esferas do poder público (federal, estadual e municipal), através de diversos órgãos setoriais, instituições nãogovernamentais (ONGs), empresas privadas com sede na região e representantes das diversas organizações e associações de moradores das comunidades. Nesse sentido, o DLIS impôs um novo diálogo entre os diversos atores, buscando a convergência na eleição de prioridades locais, colocando em xeque a estrutura e o planejamento setorial já consolidados, nos quais cada instituição, órgão ou entidade envolvida é permanentemente pautada por uma lógica particular na execução de suas ações.

Alterações e mudanças de rumo tão freqüentes diante de um elenco considerável de instituições parceiras e atores contribuíram para a dificuldade na integração das metas intersetoriais pretendidas. É forçoso reconhecer a liderança exercida pela prefeitura e a Fiocruz, o 
que conferia ao processo de implantação do DLIS credibilidade política e técnica. Se a integração entre projetos e iniciativas em uma agenda constitui estratégia central para o desenvolvimento do programa, foi exatamente essa extensa rede de parceiros que, se em um primeiro momento indicava adesão e compromisso com a proposta, irá revelar, posteriormente, a fragilidade do processo.

Assim, o processo de eleição para a Prefeitura da Cidade do Rio de Janeiro e a posse no executivo municipal de outro grupo político resultaram na desmobilização deste parceiro-chave, dificultando a implementação de uma gestão compartilhada. Da mesma forma, mudanças de gestão no âmbito da ENSP/Fiocruz, instituição em grande parte responsável pela mobilização dos demais parceiros, também colaborou para a desmobilização e, conseqüentemente, para a redefinição dos rumos do Programa.

Dessa forma, um dos maiores desafios iniciais ao desenvolvimento da proposta relaciona-se à capacidade de estabelecer um processo sustentável de interlocução entre os diversos níveis da gestão pública e entre os diversos setores administrativos. No caso de Manguinhos o afastamento da esfera municipal, abrindo mão de seu papel-chave em toda a mobilização inicial, significou a perda de sustentação política da proposta. O padrão histórico de omissão do poder público em relação às comunidades que compõem o complexo de Manguinhos visà-vis aos crescentes níveis de exclusão e de violência no local não foi equacionado. Fragmentação institucional, descontinuidade administrativa e a dificuldade em propor agendas integradas apareceram como grandes obstáculos ao sucesso do programa.

\section{Mobilização comunitária}

Propostas sociais inovadoras preocupadas com os determinantes da saúde pressupõem o conhecimento da dinâmica inerente às organizações sociais presentes nas comunidades envolvidas, como demonstram as novas abordagens avaliativas em promoção da saúde (Potvin et al., 2001; Potvin \& Chabot, 2002). Quando mudanças sociais abrangentes constituem o foco das intervenções, é necessário incluir a reflexão sobre processos socioculturais que moldam a dinâmica do desenvolvimento local.

No caso de Manguinhos, a identificação desses processos esteve vinculada à perspectiva das organizações sociais, da vida associativa e da maior ou menor predisposição para iniciativas em parceria e ações de cooperação. Solidariedade, integração, coesão, confiança e disposição para o trabalho colaborativo são fatores determinantes para o êxito das propostas de mudança. A análise do capital social, tão importante em diversas correntes do pensamento sociológico contemporâneo (Coleman,1990; Putnam, 1996), vem atualmente ganhando destaque nas discussões sobre desenvolvimento comunitário e promoção da saúde (Hawe \& Shiell, 2000; Lochner et al.,1999; Kawachi et al., 1997).

Assim, o ponto de partida do DLIS foi a realização de estudos e diagnósticos que, utilizando-se de diversas estratégias metodológicas, permitiram atualizar o conhecimento territorial e sociocultural da área, e mobilizar os moradores e lideranças locais para a discussão sobre o programa. O Diagnóstico Rápido Participativo (DRP) (Fundação Centro de Defesa dos Direitos Humanos Bento Rubião, 2000) foi uma iniciativa extremamente importante para que o programa chegasse até aos moradores, fosse assim conhecido e debatido pelas lideranças e atores políticos do local. Atualizou e deu visibilidade às reivindicações e demandas das diversas comunidades que compõem o Complexo, tendo o mérito de identificar organizações, atores e personagens que, sem dúvida, caracterizam o capital social e a vida associativa presente em Manguinhos, abrindo uma possibilidade real de parceria e de envolvimento da comunidade no processo de desenvolvimento local. O DRP permitiu a mobilização e participação das onze comunidades que compunham o Complexo de Manguinhos em torno do DLIS (Fundação Centro de Defesa dos Direitos Humanos Bento Rubião, 2000).

Nesse processo foi crucial identificar valores ligados à capacidade associativa, reforçando as redes de solidariedade existentes, as expectativas e responsabilidades compartilhadas dentro de um contexto sociocultural específico. A idéia básica é de que o sucesso das iniciativas e intervenções sociais depende em grande parte da capacidade associativa e de cooperação das populações envolvidas. O pressuposto é de que, quanto maior a coesão e a confiança, e, portanto, o capital social, reforçando a ação coletiva e interdependência, maior facilidade na obtenção de bens públicos (Coleman, 1990). Tratase, portanto, de reforçar estratégias voltadas para mudanças organizacionais e de reforço à cidadania e à ação coletiva. Importa enfatizar 
que o caminho para o desenvolvimento social e para a promoção da saúde, como afirmamos anteriormente, inclui o reconhecimento dos contextos socioculturais locais, onde capacidades e formas organizativas específicas precisam ser aprendidas. A percepção e o sentido de comunidade, a capacidade reflexiva da população e dos principais atores locais são cruciais para o êxito das propostas e para o processo de mudança. A compreensão da maneira pela qual a população identifica, elabora e vocaliza necessidades e demandas, bem como vislumbra soluções e encaminhamentos possíveis, constitui o objetivo da fase de diagnóstico participativo e o fio condutor de todo o processo.

O diagnóstico participativo realizado em Manguinhos cumpriu, assim, dois objetivos fundamentais: discussão em torno das necessidades/demandas das comunidades e a mobilização em torno das propostas e medidas com potencial para equacionar a situação de exclusão social, reforçando a participação e compromisso das lideranças e das organizações sociais nas soluções e mudanças planejadas. Nessa perspectiva foi fundamental a identificação dos chamados mediadores, moradores mais antigos e respeitados pelas comunidades, permitindo a discussão de diversos aspectos da história, da cultura e da vida associativa no local. Esses moradores, personagens reconhecidos e respeitados, foram cruciais para a permanência de valores ligados à sociabilidade, solidariedade e confiança. Enfim, o diagnóstico participativo desencadeou novas estratégias de articulação com a comunidade, incentivando a base associativa, os canais de participação e de ação coletiva existentes (Fundação Centro de Defesa dos Direitos Humanos Bento Rubião, 2000).

Metodologicamente, foram analisados os principais aspectos levantados pelo diagnóstico e enfatizado a heterogeneidade das comunidades e de seus habitantes, bem como a diversidade de formas organizativas e iniciativas sociais para a região. A configuração de ocupação da área apresenta uma disposição altamente complexa, marcada por diferenças ambientais e socioeconômicas, embora em um ambiente cujo denominador comum é a baixa renda, jovens sem escola e sem trabalho, a violência e a ausência de serviços públicos.

\section{Guia de Equipamentos e Iniciativas Sociais de Manguinhos}

Com o objetivo de aprofundar o diagnóstico das potencialidades e alternativas existentes na região foi desenvolvida uma pesquisa participativa, visando à elaboração e discussão da rede de serviços e instituições públicas, iniciativas, projetos sociais e experiências associativas nos limites do Complexo de Manguinhos (Bodstein et al., 2002). A partir dos dados e informações coletados foi editado o Guia de Equipamentos e Iniciativas Sociais de Manguinhos, que serviu ainda como estratégia complementar ao processo de mobilização e discussão em curso nas comunidades, aprofundando o debate em torno da enorme precariedade da oferta de bens e equipamentos sociais. Diante das necessidades e demandas, o Guia representou um instrumento de informação e de possível colaboração entre as diversas iniciativas presentes na área, que em sua maioria atuam de forma desarticulada, ignorando até mesmo a existência de iniciativas semelhantes. Revelou ainda o desconhecimento dos moradores em relação às comunidades vizinhas e à urgência de estabelecer uma interlocução mínima entre organizações e iniciativas, potencializando os resultados e, sobretudo, evitando a duplicação de esforços.

De modo geral, foi possível observar uma série de organizações desenvolvendo projetos voltados, direta ou indiretamente, para a população jovem. O grande número de iniciativas na área do lazer, educação e cultura, em relação às demais, reforça a importância desta temática para o desenvolvimento local, assim como o necessário questionamento em relação à cobertura e à qualidade do acesso à educação e às oportunidades de trabalho.

Iniciativas e projetos de promoção da cidadania e de prevenção à criminalidade, voltados para crianças e jovens, como o Guia evidenciou, predominam na área e são reconhecidos como de extrema importância pelas lideranças locais. A temática do lazer, da cultura e dos esportes é vista, sem dúvida, como uma alternativa para a ociosidade dos jovens nas comunidades e uma prioridade entre as demandas locais. Foi possível avaliar tanto a precariedade dos investimentos públicos nesse setor, como a existência de um número considerável de iniciativas comunitárias relacionadas às organizações do terceiro setor que, embora autônomas e criativas, não contam com recursos suficien- 
tes (Peres, 2004). Em Manguinhos, em contraste com outros grandes complexos de favelas da cidade, ainda não se tem notícia de nenhuma iniciativa de maior apelo e vulto que revele o talento e o potencial criativo dos jovens das comunidades locais. Manguinhos aparece freqüentemente nos principais jornais do Rio de Janeiro, porém, infelizmente as notícias sempre se referem à violência existente no local.

Por outro lado, foi possível observar um processo recente de mobilização e de revitalização da comunidade, cujo indicador é dado pelo ressurgimento de espaços e novas iniciativas voltadas para jovens, mulheres, idosos, soropositivos, doentes crônicos, portadores de deficiência, educação ambiental, entre outras (Bodstein \& Zancan, 2003; Zancan et al., 2002).

O levantamento das principais demandas locais e a elaboração de diagnósticos participativos, sem dúvida, devem ser vistos como precondição para o processo de mobilização e de discussão dos programas e estratégias de intervenção, principalmente em contextos de violência e de graves problemas sociais, como no caso de Manguinhos. Permitem a sensibilização e co-responsabilização dos atores tanto em relação aos problemas e às prioridades locais, como em relação ao encaminhamento das soluções possíveis. Com efeito, a participação dos moradores na elaboração do Guia, em particular, representou um processo de "empoderamento" e de mobilização relevante para as comunidades e uma estratégia importante de revitalização e discussão do DLIS.

\section{Fórum e vida associativa local}

Após um ano e meio de início do programa, indicando o grau de aceitação e de envolvimento das lideranças locais com a proposta, foi constituído o Fórum Comunitário "Acorda Manguinhos", previsto como etapa final da mobilização em torno do DRP e dos diversos encontros de discussão do DLIS (Fundação Centro de Defesa dos Direitos Humanos Bento Rubião, 2000; Bodstein \& Zancan, 2003). O Fórum teve como perspectiva reunir as lideranças e representantes das associações de moradores e de diversas iniciativas locais, reforçando a participação dos moradores nos vários setores de atuação do DLIS. Representou, portanto, uma estratégia para a revitalização da vida associativa através da formação de novas parcerias em um novo espaço decisório, potenciali- zando a discussão em torno da melhoria das condições de vida e saúde em Manguinhos.

É importante frisar que o processo de construção de um novo espaço de interlocução e de negociação entre as principais representações locais constituiu, do ponto de vista da história local, uma grande inovação. A constituição e o funcionamento do Fórum, em um primeiro momento, revelaram a capacidade de mobilização e de resposta rápida das lideranças à convocação de um programa até bem pouco tempo atrás desconhecido. As reuniões do Fórum, reunindo mais de 60 pessoas, traduziram um momento de extremo otimismo, esperança e expectativas positivas diante do relativo consenso criado em torno da implantação do DLIS. De fato, a constituição do Fórum significou um esforço de superação de conflitos e perspectivas divergentes entre as lideranças locais, exigindo para seu funcionamento uma complexa negociação política.

Assim, a perspectiva de implantação de um programa com o perfil do DLIS induziu ao diálogo entre representantes formais das 11 comunidades, isto é, das Associações de Moradores, e entre estes e as lideranças vinculadas às novas organizações sociais e, portanto, a um novo associativismo atuante no Complexo. No entanto, um ano depois, em meados de 2002, foi possível não só perceber o esvaziamento do Fórum e das expectativas que despertara, mas alguns desafios que o programa como um todo enfrentava.

Da perspectiva da avaliação importava buscar explicações para esse processo inicial de intensa mobilização e de gradativa desmobilização. O processo de constituição do Fórum, sua proposta e atuação e de superação da prática política tradicional constituíram questões centrais da análise e da metodologia de avaliação. Assim, através de entrevistas com as lideranças locais, foram levantadas questões em torno da dinâmica da vida associativa local, do sentido de identidade e coesão, das redes de solidariedade existentes e das expectativas e responsabilidades compartilhadas, bem como a diversidade de significados e representações sobre a prática política cotidiana das lideranças locais presentes no Fórum (Bodstein \& Zancan, 2002; 2003; Peres, 2004).

A análise revelou uma disputa de poder no interior do Fórum, um clima de desconfiança e acusações veladas, gerando dificuldades concretas para a cooperação e a ação coletiva, fundamentais naquele momento para o diálogo qualificado com os técnicos, gestores do pro- 
grama e com o poder público. Estava em jogo um novo arranjo do espaço decisório local, que enfrentava interesses já consolidados, no qual o diálogo entre experiências diversas e conflitantes de mobilização e de associativismo constitui um desafio permanente. Revelou ainda que, se por um lado, havia consenso sobre a importância do DLIS e do Fórum para encaminhar e negociar soluções, por outro, havia o predomínio de práticas políticas marcadas pelo imediatismo, personalismo e assistencialismo. Isto é, impasses na construção desse processo vieram do fato de alguns atores e líderes tradicionais terem sentido sua legitimidade e representatividade ameaçadas, sem que se vislumbrassem ganhos e retornos imediatos com o Fórum e com o programa DLIS. Essas práticas políticas tradicionais tornam-se evidentes e particularmente acirradas em momentos de eleição, quando promessas eleitorais de curto prazo são renovadas. Manguinhos, como toda comunidade de baixa renda da cidade, sofreu influência deste processo. O momento de desmobilização do DLIS e do próprio Fórum coincide com as eleições para o legislativo municipal e prefeitura em 2000 quando as disputas político-partidárias se intensificam.

Cabe enfatizar que um ponto fundamental em relação ao enfraquecimento do Fórum residiu tanto em fatores vinculados às eleições municipais como, sobretudo, a lógicas distintas de atuação política entre as próprias lideranças locais. Ou seja, foi possível observar uma profunda diversidade de interesses e de práticas de atuação política entre os representantes das associações de moradores, por um lado, e as lideranças vinculadas ao chamado novo associativismo, ou seja, as organizações sociais (ONGs) atuantes em Manguinhos. Os conflitos, críticas e acusações mútuas entre os dois grupos acabaram por prevalecer, gerando desconfiança, impedindo a formação de um circuito de cooperação e articulação política em torno das demandas e projetos locais. Foi possível analisar através da constituição e funcionamento do Fórum os impasses na ação coletiva dada pela ausência de confiança e colaboração (Putnam, 1996; Bodstein \& Zancan, 2002; 2003; Peres, 2004). Disputas internas opondo distintas lógicas de atuação política geraram dificuldades insuperáveis ao processo de pactuar, inviabilizando a consolidação de uma agenda local integrada, apesar do relativo incremento nas parcerias e continuidade na proposição de projetos e iniciativas sociais.
Por outro lado, a unanimidade e convergência de interesses, como foi possível perceber, surgiram em torno das propostas e atividades de promoção à saúde, educacionais, sócio-recreativas e culturais. Importa perceber que não só essas iniciativas mas sobretudo festas e danças, músicas e capoeira, campeonatos de futebol, blocos de carnaval, como a literatura vem apontando, desempenham não só um papel fundamental para o reforço da identidade e da coesão social, como ajudam na constituição e renovação de lideranças e mediadores locais (Alvito, 2001). No caso de Manguinhos, ainda que bastante tímidas e incipientes, apareceram, sem dúvida, como importante fator de sociabilidade e agregação de interesse entre lideranças comunitárias e o próprio Fórum (Peres, 2004).

Mobilização, coesão social e manifestações socioculturais importam fundamentalmente para a auto-estima e identidade das comunidades, fortalecendo e legitimando vínculos sociais. Viabilizam compromissos, acordos e, portanto, o capital social das comunidades, abrindo a possibilidade de um diálogo inovador com o poder público e com os projetos e iniciativas sociais. Como vimos, a literatura atual sobre a avaliação de iniciativas comunitárias e de promoção da saúde mostra exatamente que a efetividade dos programas depende em grande parte do chamado capital social e da cultura cívica local. Portanto, estratégias de fortalecimento dos vínculos sociais são componentes cruciais da sociabilidade local, dos programas e das metodologias de avaliação (Lochner et al., 1999; Potvin et al., 2002; Stolle, 2000).

Capital social, segundo a tradição sociológica clássica que Coleman traduz, remete às características da estrutura social que dizem respeito aos níveis de confiança interpessoal, normas de reciprocidade e auxílio mútuo que facilitam ações cooperativas. Tais características dependem, segundo o autor, da ausência de conflito social latente (manifestada por grandes desigualdades sociais); tensões raciais ou étnicas; disparidades em participação política e outras formas de polarizações, e a presença de fortes vínculos sociais - medida por níveis de confiança e normas de reciprocidade; abundância de associações que ligam e minimizam as divisões sociais; presença de instituições para dirimir conflitos (democracia participativa e um judiciário independente, entre outras) (Coleman, 1990).

Dessa forma, apesar do mérito indiscutível do conceito e de seus desdobramentos para o campo da saúde, convém relativizar sua aplica- 
ção e enfatizar que lidamos no caso das experiências analisadas com contextos de extrema violência e desigualdade social, marcado por carências de infra-estrutura urbana e de serviços básicos (habitação, saneamento, educação e saúde), nos quais a presença do poder público é simplesmente crucial. Em Manguinhos o que está em jogo é a preservação do sentido de comunidade, de coesão, de solidariedade, de confiança no poder público, ameaçados pela exclusão social e pela presença do crime organizado. Capital social em Manguinhos, como para as demais áreas de baixa renda no Rio de Janeiro, diz respeito sobretudo à segurança pública, promoção da cidadania e da inclusão social o que, sem dúvida, torna o debate sobre programas de desenvolvimento local e promoção da saúde extremamente complexo.

\section{Considerações finais}

A experiência com o processo de avaliação em Manguinhos evidenciou - assim como a literatura tem ressaltado - os limites dos modelos tradicionais de avaliação, baseados em fases distintas e sucessivas, ou seja, etapa do diagnóstico participativo; planejamento; implementação e fase de impacto e sustentabilidade.

Mostrou a necessidade de buscar novas metodologias de avaliação que considerem a complexidade intrínseca que envolve programas comunitários, permeados por múltiplas influências externas e variáveis contextuais não controláveis (Potvin, 1996). Abordagens qualitativas do processo de implementação de programas sociais têm o mérito de revelar a dinâmica e a multiplicidade de atores, interesses e estratégias com que se defrontam as propostas e iniciativas.

No caso de Manguinhos, como vimos, a principal inovação introduzida com o DLIS foi, por um lado, a formação de diversas parcerias, sendo a Fiocruz uma indiscutível liderança neste processo e a ênfase nas ações intersetoriais, onde a chamada macrofunção da Prefeitura desempenhou o papel de carro-chefe. Porém, o efeito do Programa e seu resultado mais palpável, ainda que intermediário, atrelou-se menos às questões da gestão e do planejamento e mais à compreensão da dinâmica de mobilização e organização das comunidades locais suas disputas e conflitos internos e relações com o poder público - dinâmica capaz de desencadear ou de obstaculizar impactos e resultados mais consistentes na qualidade de vida.
Importou avaliar e discutir a participação comunitária no processo de formulação de uma agenda de desenvolvimento local e promoção da saúde. Nesse caso, o que esteve em jogo foram mudanças sutis nos mecanismos de democratização, ampliação da interlocução e da formação de parcerias em Manguinhos, visando à constituição de um novo processo decisório e de uma agenda local com sustentabilidade política. A proposta do DLIS, sem dúvida, mobilizou as lideranças comunitárias e os mediadores, permitindo um indiscutível revigoramento das formas de associação e de representação dos interesses locais. Porém, como nos lembra Jacobi tais mecanismos são sempre de mão dupla. O poder público, abrindo canais de participação, ampliando o espaço público, acaba por capacitar os representantes comunitários que se co-responsabilizam pelas mudanças programadas (Jacobi, 2002).

Considerando a participação da administração municipal, o que se viu em Manguinhos foi um processo incerto e de relativa abertura seguido de um visível recuo e distanciamento. O diálogo e a interlocução ampliada e qualificada entre os atores envolvidos foi difícil. Foi possível observar o predomínio de uma prática clientelista e fisiológica, que parece permanecer intacta ao longo dos anos: programas e ações são implantados nas comunidades, visando aos ganhos eleitorais imediatos. Assim, a sustentabilidade política da proposta de DLIS não ocorreu, inviabilizando o pacto de uma agenda comum.

Vale reafirmar que o principal desafio para a definição de uma agenda traduziu-se na dificuldade de alcançar consenso sobre os principais parceiros, estratégias e prioridades de médio e longo prazo. De fato, estas dificuldades apontaram para a necessidade de superação de alguns dos conflitos presentes entre as lideranças comunitárias que operam com uma lógica política tradicional. Trazer à tona e criar estratégias para lidar com estas situações podem colaborar para melhor efetividade das ações propostas, assim como estimular o cooperativismo e a confiança entre os atores - que, aliás, constitui-se num dos principais entraves para a sustentabilidade das iniciativas intersetoriais e participativas. Nessa perspectiva, foi enfatizada a importância das atividades culturais, recreativas e esportivas como um caminho possível de fortalecimento de vínculos sociais e de maior coesão entre as comunidades que compõem o complexo de Manguinhos. 
Além disso, foi possível constatar que impactos mais efetivos na qualidade de vida em áreas de grande concentração de favelas e moradias improvisadas, dependem fundamentalmente da expansão e melhoria da oferta de bens e serviços sociais básicos, em que a presença e responsabilidade do poder público são cruciais.

Por fim, a execução do Programa e a sustentabilidade da proposta como um todo foram (e continuam sendo) desafiadas pelo agravamento da violência na região, passando pela fragilidade do poder público e pela própria di-

\section{Colaboradores}

R Bodstein trabalhou na concepção teórica, levantamento bibliográfico e na discussão conceitual; L Zancan, na discussão teórico-conceitual, e na supervisão do trabalho de campo; CL Ramos, no desenho de instrumento de coleta de dados; e WB Marcondes no desenho do instrumento e trabalho de campo.

\section{Referências bibliográficas}

Alvito M 2001. As cores de Acari: uma favela carioca. FGV, Rio de Janeiro.

Barnes M, Matka E \& Sullivan H 2003. Evidence, understanding and complexity: evaluation in non-linear systems. Evaluation 9(3):265-285.

Bodstein R \& Zancan L 2003. Monitoramento e avaliação do Programa de Desenvolvimento Local Integrado e Sustentável (DLIS) - Manguinhos. Relatório de Pesquisa. Rio de Janeiro, Finep.

Bodstein R \& Zancan L 2002. Avaliação das ações de promoção da saúde em contexto de pobreza e vulnerabilidade social, pp. 39-59. In L Zancan; R Bodstein \& WB Marcondes (orgs.). Promoção da saúde como caminho para o Desenvolvimento Local: a experiência em Manguinhos - RJ. Abrasco, Rio de Janeiro.

Bodstein R, Zancan L \& Estrada D 2001. Guia de Equipamentos e Iniciativas Sociais em Manguinhos. Finep, Rio de Janeiro.

Buss PM 1999. Promoção da saúde e a saúde pública: uma contribuição para o debate entre escolas de Saúde Pública da América Latina e Caribe. (Mimeo).

Buss PM \& Ramos C 2000. Desenvolvimento local e agenda 21. Desafios da cidadania. Rio de Janeiro. COEP. Cadernos da Oficina Social 3:13-65.

Coleman JS 1990. Foundation of Social Theory. Harvard University Press, Cambridge, Massachusetts-Londres, Inglaterra. nâmica política e associativa local, onde diálogo, confiança e cooperação são, no mínimo, problemáticos. Assim, mobilização e organização da população vis-à-vis mudanças nas práticas institucionais - precondição para equacionar o problema da violência, permitindo a discussão continuada dessa e de outras propostas de melhoria local -, foram enfatizadas como elementos centrais do programa e da perspectiva avaliativa, levando em conta os impasses a serem superados na escolha dos critérios e medidas que lhes representem.
Denis JL \& Champagne F 1997. Análise da implantação, pp. 49-88. In Z Hartz (org.) Avaliação em saúde: dos modelos conceituais à prática na análise da implantação dos programas. ENSP/ Fiocruz, Rio de Janeiro.

Ferreira JR \& Buss PM 2002. O que o desenvolvimento local tem a ver com a promoção da saúde? pp. 15-38. In L Zancan, R Bodstein \& WB Marcondes (orgs.). Promoção da saúde como caminho para o Desenvolvimento Local: a experiência em Manguinhos - RJ. Abrasco, Rio de Janeiro.

Fundação Centro de Defesa dos Direitos Humanos Bento Rubião 2000. Diagnóstico rápido e participativo das comunidades que compõem o Complexo de Manguinhos. Fundação Bento Rubião, Rio de Janeiro. (Mimeo).

Giddens A 2002. Modernidade e identidade. Jorge Zahar, Rio de Janeiro.

Hakin C 1999. Research design (successful designs for social and economic research). 2a ed. Social Research Today. Martin Bulmer (ed.). Routledge-Londres.

Hartz Z 1999. Pesquisa avaliativa em promoção da saúde, p. 178. In PM Buss (org.). Promoção da saúde e saúde pública: contribuição para o debate entre as escolas de Saúde Pública da América Latina. (Mimeo).

Hawe P \& Shiell A 2000. Social capital and health promotion: a rewiew. Social Science and Medicine 51:871885 . 
Jacobi P 2002. Políticas sociais locais e os desafios da participação citadina. Revista Ciência e Saúde Coletiva 7(3):443-454.

Kawachi I, Kennedy BP \& Lochner K 1997. Long live community: social capital as public health. The American Prospect, nov. dez.:56-59.

Krutman HM 2004. Fatores críticos no êxito de projetos de Desenvolvimento Local Integrado e Sustentável (DLIS). Tese de doutorado. Universidade Federal do Rio de Janeiro, COPPE. Rio de Janeiro, 142pp.

Lochner K, Kawachi I \& Kennedy B 1999. Social capital. A guide to its mesurement. Health and Place 5:259-270.

Majchrzak A 1984. Methods for policy research. (Applied Social Research Methods series 3). Sage Publications, Newbury Park, EUA.

McKinlay JB 1996. More appropriate evaluation methods for community - level health interventions (introduction to the special issue). Evaluation Review 20(3):237-243.

Minkler M \& Wallerstein N (eds.) 2003. Community based participatory research for health. Jossey - Bass, São Francisco.

Pawson R 2003. Nothing as practical as a good theory. Evaluation 9(4):471-490.

Pawson R 2002. Evidence-based policy: in search of a method. Evaluation 8(2):155-156.

Pawson R \& Tilley N 1997. Realistic evaluation. Sage, Londres.

Peres FF 2004. Lazer e cultura na agenda local: mobilização $e$ ação coletiva em Manguinhos. Dissertação de mestrado. Escola Nacional de Saúde, Fundação Oswaldo Cruz. Rio de Janeiro, Rio de Janeiro. 132pp.

Petersen DM 2002. The potencial of social capital measures in evaluation of comprehensive community based health initiatives. American Journal of Evaluation 23(1).

Pluye P, Potvin L \& Denis JL 2004. Making public health programs last: conceptualizing sustainability. Evaluation and Program Planning, 1-13 (no prelo).

Potvin L 1996. Methodological challenges in evaluation of dissemination. Canadian Journal of Public Health 87(2):nov-dec.
Potvin L \& Richard L 2001. The evaluation of community health promotion programs. Evaluation in Health Promotion. Principles and Perspectives. World Health Organization, Copenhagen: 213-240.

Potvin L, Haddad S \& Frohlich L 2001. Beyond process and outcomes evaluation: a comprehensive approach for evaluating health programs, pp. 45-62 . In IG Rootman et al. (eds.). Evaluation in health promotion. Principles and perspectives. World Health Organization, Copenhagen.

Potvin L \& Chabot P 2002. The splendour and misery of epidemiology (no prelo).

Putnam R 1996. Comunidade e democracia: a experiência da Itália Moderna. FGV, Rio de Janeiro.

Reis INC et al. 2002. Promoção da saúde e reorientação de serviço: a experiência do Centro de Saúde Escola Germano Sinval Faria, pp. 111-158. In L Zancan, R Bodstein \& WB Marcondes (orgs). Promoção da saúde como caminho para o Desenvolvimento Local: a experiência em Manguinhos - RJ. Abrasco, Rio de Janeiro.

Rootman IG et al. 2001. Introduction and framework, pp. 3-7. In IG Rootman et al. (eds.). Evaluation in health promotion: principles and perspectives. World Health Organization, Copenhagen.

Stolle D 2000. Social capital: a new research agenda? Towards an attitudinal approach. ECPR Workshop 13: Voluntary Association, Social Capital and Interest Mediation, Copenhagen.

Sullivan H, Barnes M \& Matka E 2002. Building colaborative capacity trough 'theories of change'. Early lessons from the evaluation of Health Action Zones in England. Evaluation 8(2):205-226.

Wallerstein N \& Martinez L 1994. Empowerment evaluation: a case of an adolescent substance abuse prevention program in New Mexico. Evaluation Practice 15:131-198.

Zaluar A 1997. Exclusão e políticas públicas: dilemas teóricos e alternativas políticas. Revista Brasileira de Ciências Sociais 12:29-47.

Zancan L, Bodstein R \& Marcondes WB (orgs.) 2002. Promoção da Saúde como Caminho para o Desenvolvimento Local: a experiência em Manguinhos - RJ. Abrasco, Rio de Janeiro.

Artigo apresentado em 26/4/2004

Aprovado em 20/6/2004

Versão final apresentada em 30/6/2004 